\title{
Extraction of underwater fragile artifacts: research status and prospect
}

\author{
Xue-Qiang Chen ${ }^{1,2^{*}} \mathbb{D}, \mathrm{Ke} \mathrm{Xia}^{1}$, Wenjing $\mathrm{Hu}^{1}$, Ming Cao ${ }^{1}$, Kai Deng ${ }^{3}$ and Shiqiang Fang ${ }^{1 *}$
}

\begin{abstract}
There are still many difficulties in the recovery and long-term preservation of underwater archaeological artifacts, in situ preservation should be the first choice before further procedures are considered. However, the materials, preservation status, and preservation environment of underwater artifacts are diverse, resulting in many fragile artifacts facing difficult situations. In order to prevent serious damage, it is a safe protective strategy to preserve them in a controlled environment for a long time after excavation. Extraction and transfer of fragile cultural relics are vital parts of this strategy. Due to the complexity of the underwater environment and the vulnerability of fragile artifacts, safety in extraction and transfer still faces enormous challenges. Researchers have developed new materials and technologies to tackle this problem. This paper focuses on introducing and developing prospects to different preservation techniques for fragile artifacts from underwater sites.
\end{abstract}

Keywords: Underwater cultural heritage, In situ conservation, Underwater fragile artifacts, Underwater archaeology, Extraction technology

\section{Introduction}

Ancient peoples explored, adapted, and prospered the ocean, which carries great cultural significance. It paved the way for material and cultural contacts, facilitated intercultural conversation and mutual impact, and fostered the cultural fusion of ancient civilizations [1-3]. Since antiquity, many ancient ships and coastal relics have sailed/sunk into the ocean. Their remains still lie on the seafloor and may be protected safely. Over the past few centuries, land-based archaeological sites have gained a wealth of important information about past civilizations. But there are still many secrets to explore in the vast ocean. They bear witness to human activity at various stages of history, including material exchanges, peaceful exchanges and intercultural dialogues between remote regions, brutal wars and shipwrecks $[4,5]$.

\footnotetext{
*Correspondence: xqchen1990@163.com; fangshiqiang@gmail.com ${ }^{1}$ Cultural Property Protection Center, Ningbo University of Finance \& Economics, Ningbo 315175, China

Full list of author information is available at the end of the article
}

Underwater cultural heritage is a significant wealth of all countries of the world and all humanity, and the witness of the people to understand, think about and learn from history. They reflect human activity at different times in history and primarily contain the following historical information: (1) Material and cultural exchange [6-8]: various countries globally have realized material exchange and cultural integration in different regions through waterborne trade, thus creating various handicrafts and cultural forms. (2) History of science and technology [9]: production tools and living utensils used by ancient people have been unearthed from land archaeological sites, which were once brought to ships for use or exported to other countries. These remains and production techniques that are valuable historical materials reflect the development of social science and technology in a period and a specific area. (3) History of shipbuilding $[10,11]$ : the design conception and construction of ships was closely related to the past's socio-economic, political, and social background. The design and construction of vessels varied greatly from different countries and historical periods, detailed records of cargo ships and

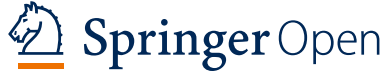

(c) The Author(s) 2022. Open Access This article is licensed under a Creative Commons Attribution 4.0 International License, which permits use, sharing, adaptation, distribution and reproduction in any medium or format, as long as you give appropriate credit to the original author(s) and the source, provide a link to the Creative Commons licence, and indicate if changes were made. The images or other third party material in this article are included in the article's Creative Commons licence, unless indicated otherwise in a credit line to the material. If material is not included in the article's Creative Commons licence and your intended use is not permitted by statutory regulation or exceeds the permitted use, you will need to obtain permission directly from the copyright holder. To view a copy of this licence, visit http://creativecommons.org/licenses/by/4.0/. The Creative Commons Public Domain Dedication waiver (http://creativeco mmons.org/publicdomain/zero/1.0/) applies to the data made available in this article, unless otherwise stated in a credit line to the data. 
warships in various periods of history. At the same time, shipwrecks provide a great deal of physical information. Wrecks contain the wisdom of ancient people and have significant historical value. (4) History of the wars [12, 13]: there have been innumerable sea wars, and many ships have sunk due to the cruel wars. A shipwreck can provide us with a wealth of information, weapons, and goods that can decrypt the battle for us and the warship details and verify or supplement relevant historical literature. (5) Prehistoric civilization and natural changes $[14,15]$ : due to the long history of prehistoric society, the sites will experience changes in the surrounding natural environment in the process of formation, which creates the diversity of cultural layer distribution of the site. As there is a potential causal relationship between environmental changes and cultural layer changes, forming a cultural layer can provide an essential basis for changing the natural environment in specific regions.

Although there are differences in buried environments between underwater and on-land cultural heritages, they have witnessed the historical creation and cultures in the world $[16,17]$. At the same time, underwater heritage is also the extension and supplement of the land's cultural heritage. In addition, some land-based sites have become part of the underwater cultural heritage due to historical and natural changes. Many land-based architectural areas have been inundated due to different reasons, such as earthquakes, ground subsidence, and sea-level rise [18-22].

\section{The analysis of in-situ preservation and archaeological excavation}

In 2001, UNESCO proposed in situ preservation as the primary principle for "the Protection of the Underwater Cultural Heritage" [23, 24]. Due to many underwater sites, especially shipwrecks, archaeological excavation usually costs a tremendous workforce and financial resources. It isn't easy to implement the recovery of each underwater site. In addition, artifacts have been buried underwater for a long time, and once they are out of water may cause an accelerated corrosion process $[25,26]$. The erosion rate of the surrounding environment on the underwater cultural heritage can be slowed down by in-situ conservation methods, such as covering the isolation layer, re-burial, and building underwater museums [27-29]. However, in situ preservation involves a series of disciplines such as material science, chemistry, physics, meteorology, biology, and there are still tricky problems to solve [30]:

(1) In-situ preservation cannot prevent the chemical electrolyte and tiny microorganisms in the ocean from penetrating the surface artifacts. The chemical and biological corrosion of cultural relics in the water will always exist [31-34].

(2) The preservation states of underwater cultural heritage are diverse, and in-situ preservation cannot ensure the security of fragile underwater artifacts for the long term [35].

(3) With the development of current diving technology, the general public can easily access underwater sites. Commercial theft still exists, and human activities will bring potentially irreversible damage to the underwater cultural heritage [36-38].

(4) Fishery and energy development also inevitably threaten the underwater cultural heritage [39, 40], such as fishing nets, harbor construction, offshore oil drilling, etc.

(5) Unstable natural factors, such as geological disasters, climate change, and sea-level rise, may adversely affect cultural heritage. Underwater sites that have been buried for a long time will gradually evolve and form a relatively stable local ecosystem with the surrounding environment. Climate change will break the long-maintained equilibrium state of underwater sites, and the temperature, oxygen, inorganic salt content, and biological community around the areas will change accordingly. The change of these equilibrium factors will speed up the corrosion rate of underwater relics [41-44].

Therefore, a UNESCO statement acknowledges that careful recovery of underwater cultural heritage may be justified 'for scientific or protective purposes'; Suppose the excavation is for scientific or salvage purposes, the materials and techniques used must be non-destructive and ensure that cultural, historical, and archaeological information is retained during extraction.

\section{Preservation of underwater fragile cultural heritage}

Retrieving underwater artifacts is an irreversible and potentially damaging action. Artifacts in a poor state of preservation are challenging to excavate, stabilize, lift, and transport to the conservation site. Therefore, in situ preservation should be the first choice before evaluation, and regular/real-time monitoring of potentially vulnerable sites should be carried out. When its preservation state is at risk, recovery can be considered. Of course, it based the implementation of all these measures on the safety as a prerequisite.

\section{Underwater fragile artifacts}

The materials of underwater cultural heritage are diverse, some of which have poor corrosion resistance, such as underwater organic and metal artifacts. Under the longterm biochemical corrosion of the water environment, the artifacts above usually become extremely fragile [45], 
such as organic artifacts including wooden hulls, lacquered woodwork, plants, seeds, bones, etc. Microbes and bacteria in water can gradually nibble the organic artifacts, causing holes in the interior and the gradual disappearance of lignin, and even the result of hull fracture and the complete disappearance of the structure inside the organic artifacts. Some living utensils, handicrafts, coins, ship-borne weapons, etc., are metallic structures. After long-term chemical and biological corrosion underwater, metallic artifacts will often be seriously corroded and become fragile [46]. In addition, thin-walled porcelains are also considered fragile artifacts because of their delicate nature and inability to withstand the interference of the surrounding environment.

Artifacts with unique stacking and arrangement structures Some underwater artifacts are not fragile materials themselves, but they exist in particular distribution forms of stacked systems in the underwater sites. These distribution patterns have important archaeological information but can be easily influenced by the surrounding environment, including fractured cultural artifacts composed of multiple parts, multiple artifacts stacked together, the organic part of the artifacts being seriously eroded.

\section{The conservation of fragile underwater artifacts}

To prevent irreversible damage, special protection measures are needed to preserve fragile underwater artifacts, excavating and extracting them for protection and further research $[27,47]$. It is a conservation strategy complementary to the in situ conservation method to remove underwater artifacts and place them in a safe and controllable environment for long-term preservation [48-50]. The key to this strategy is whether the fragile artifacts can be safely extracted from water. However, because of the fragility, the safety of fragile cultural objects during the recovery process of excavation, extraction, and transfer is still a significant problem [51].

\section{Extraction technology of underwater culture heritage \\ Conventional extraction of artifacts}

The well-preserved artifacts such as stone tools, porcelain, and metal in good condition can be directly carried or collected by divers on the premise that they will not be damaged during conventional raising. It is limited to portable, well-preserved cultural relics on the site's surface. Because of the difficulty of underwater operation, it is not suitable for large-volume, poorly preserved, and easily damaged cultural relics.

\section{Extraction of artifacts in sediment}

Underwater artifacts in sediment are usually extracted by employing metal frame loading [52]. The extraction process of this method is shown in Fig. 1. During the process, the metal frame is placed on the coagulation to be extracted, and the whole structure is vertically pressed into the sand, a metal baffle is inserted horizontally and fixed on the lower surface of the metal frame, and finally, the condensate is extracted out of the water with a rope. As a packing material, framework loading is suitable for artifacts in large volumes, and it is difficult to directly use for raising fragile relics because it failed to solidify the objects.

\section{Extraction of sunken ships}

According to the preservation condition of the submerged shipwreck, the excavation process includes two methods: extraction as a whole and separate extraction. After professional evaluation for well-preserved shipwrecks, the former method can be adopted to ensure that the operation can withstand the physical stress in the raising process. Historically, there have been several successful overall extraction processes, such as the ancient British "Mary Rose," the Swedish "Vasa" battleship, and China's "Nanhai I" song dynasty wooden wreck. For example, during the excavation process of the "Nanhai

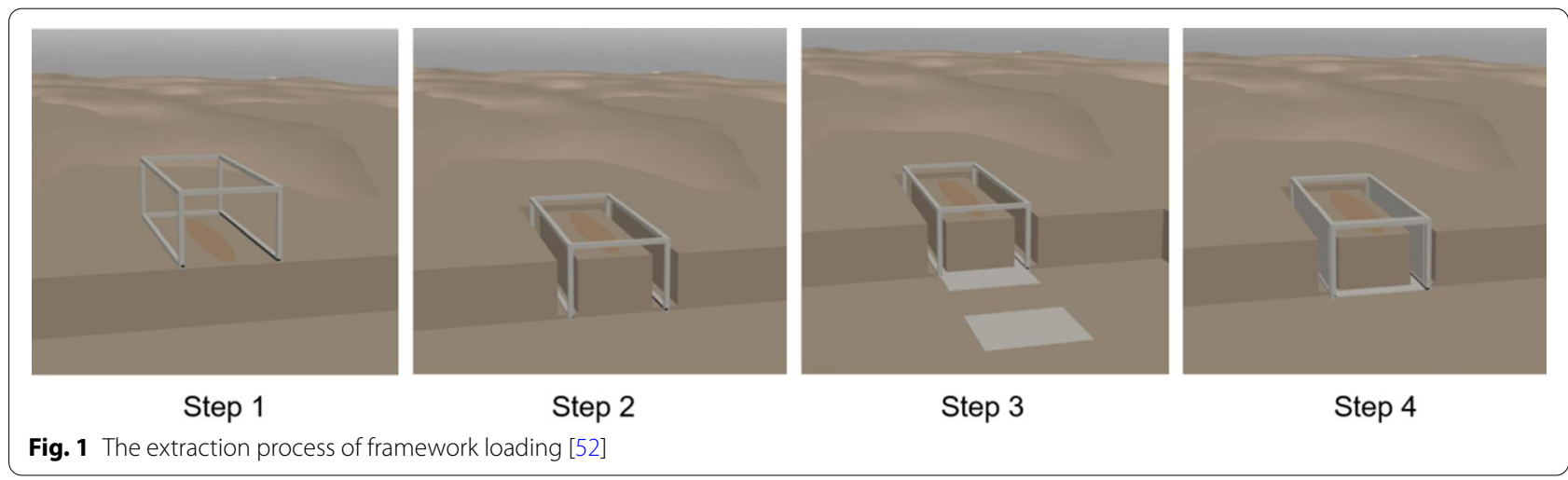


I," a vast caisson was placed over the wooden impact and pressed into the sediment at the bottom of the wreck. Then steel tubes were inserted into the bottom of the caisson to fix the hull and extract it.

The extraction of sunken ships usually requires sufficient technical and financial support. It is difficult to carry out the projects for all known sunken vessels due to many sunken underwater ships. A sunken boat is of extraction significance only if it is of archaeological importance and ensures that the hull can be safely preserved for a long time. Therefore, the in-situ preservation of underwater shipwrecks may be a safe and effective protection method at present.

\section{Research on extraction technologies of fragile underwater artifacts}

The extraction of artifacts on archaeological sites mainly adopts different overall extraction methods according to the preservation status, archaeological environment, and the volume of the artifacts. Compared with underwater sites, the research on the extraction technology of land archaeological sites is relatively mature. The methods commonly used to extract cultural relics on-land sites include (1) the cutting method: extraction depends on the strength of the soil itself. This method is suitable for the surrounding soil condition is good enough, but not for artifacts with large volumes. (2) Gypsum filling method: the whole remains and the soil around will be extracted together after reinforcement by gypsum perfusion. However, because of the high density of gypsum itself, it may not strengthen artifacts with sizable volume. (3) Encasement method: use wooden or metal frame to stabilize the soil around the artifacts. (4) Foaming material reinforcement extraction: polyurethane foaming material is used to strengthen the surrounding soil media of artifacts, which is used to strengthen artifacts with large volumes. The cutting, gypsum, and foaming material reinforcement methods are suitable for the land sites with good soil strength, so they cannot be used for artifacts in underwater sites. The method of encasement extraction is usually used to extract cultural relics from underwater condensates or the hull, as outlined above.

Underwater fragile artifacts, especially perishable organic utensils, hull and cargo, corroded and broken metal vessels, thin-walled ceramic vessels, and cultural relics with particular ordering and stacking structures, should be specially reinforced and packaged before being extracted from seabed. At present, a series of materials are usually used to support and extract underwater fragile artifacts, including containers with protective foam, polyethylene boxes, self-sealing bags, etc.

The National Museum of Denmark has carried out a critical SASMAP Project on developing equipment and methods for investigating, evaluating, stabilizing, monitoring, and protecting underwater sites. The researchers have developed various techniques for extracting fragile organic artifacts underwater, including bandage wrapping and carbon fiber/epoxy wrapping method (Fig. 2). The bandage wrapping method selects a lightweight, strong, and durable bandage used for orthopedic surgery. The bandage contains a wet-cured polyurethane resin that will cure when it encounters water or is exposed to moist air. Bandages are wound around cultural relics, and the wet curing resin in the bandages solidifies quickly after contact with water, thus strengthening it after packing the artifacts. The carbon fiber fabric impregnated with epoxy resin was applied to wrap the underwater artifacts. Before the adsorbed epoxy resin solidifies, the fragile organic artifacts are wrapped by carbon fiber. The epoxy resin is solidified to form a protective layer for the temporary storage of artifacts. The bandage and carbon fiber/epoxy methods achieve the recovery process by wrapping to form a protective shell, but the operation process needs to move the artifacts, which may face difficulties for fragile artifacts with poor preservation conditions.

\section{Temporary solidifying and extraction technology of fragile underwater artifacts}

Due to the fragility of underwater artifacts and the particularity of the existing environment, coupled with the influence of water, the current underwater archaeological extraction methods are not suitable for fragile underwater artifacts. Formal ways in the process of excavation, which not only lead to the risk of damage to fragile artifacts but also lead to the loss of archaeological information of artifacts due to the failure of undisturbed reinforcement. Therefore, it is urgent and necessary to develop a kind of extraction and reversible recovery technology for fragile artifacts in their original state.

\section{The meaning of "undisturbed underwater extraction"}

"Underwater undisturbed extraction" means that under the premise of not changing the existing state of underwater artifacts in the process of extraction and transfer. Moreover, after the fragile artifacts are extracted, the strengthening materials used can be removed safely and controllably on the premise of not affecting the state of the artifacts, restoring the original form of underwater artifacts, and achieving the reversible recovery.

\section{The significance of temporary solidifying, extraction, and reversible restoration}

The original state of the cultural relics in archaeological sites contains essential historical and cultural 


\section{（The SASMAP Project）}

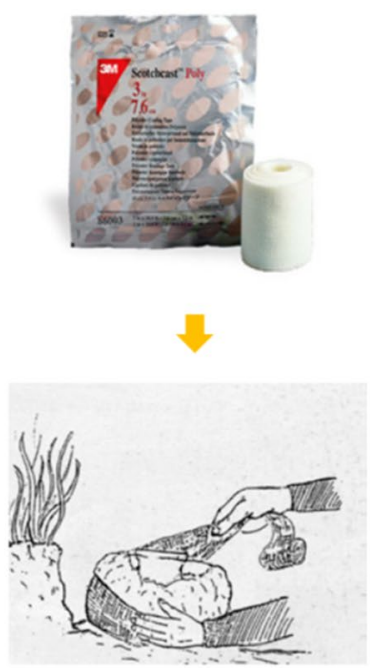

1. Bandage wrapping
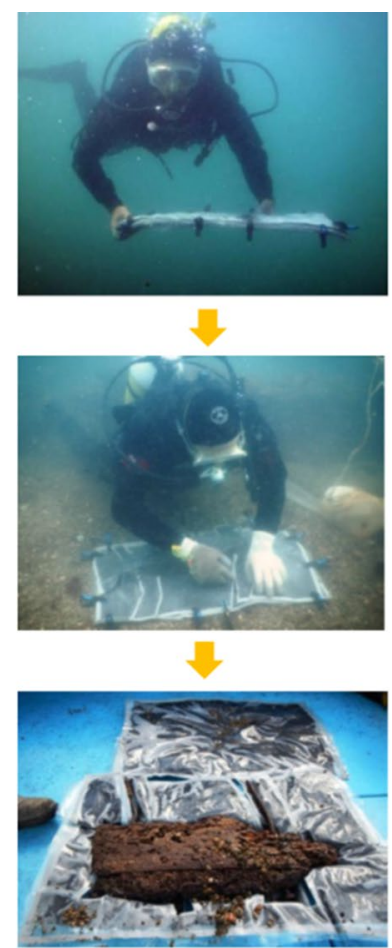

2.Carbon fiber/epoxy resin wrapping
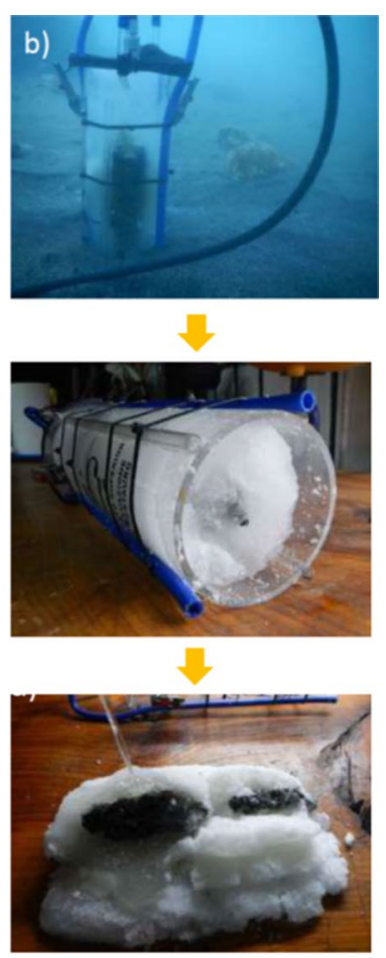

3. Freezing method

Fig. 2 The extraction method for underwater organic artifacts developed in the SASMAP Project [52]

information. Therefore, the extraction of artifacts as a whole is of great significance, and at the same time, it also helps the subsequent restoration and display of recovered objects. The underwater state represents the original appearance of artifacts in the site, which is conducive to the subsequent restoration of cultural relics and extremely important for studying ancient artifacts. Besides, visibility around underwater sites is often poor. It is often difficult to record the sunken remains completely through underwater photography, highlighting the importance of undisturbed extraction of fragile artifacts. Therefore, when the fragile underwater remains are strengthened and extracted, the existing state of the artifacts in the site must be in a brief undisturbed solid form. In addition, the reinforcement materials need to be removed in a reversible and controllable way to ensure that the artifacts can maintain their underwater state during the restoration and preservation. Therefore, it is crucial to carry out temporary undamaged solid extraction and reversible recovery for fragile artifacts underwater in excavation. The developed materials and methods should meet the basic requirements of both "underwater undisturbed extraction " and "reversible recovery after extraction."

\section{Difficulties on temporary solidifying and extraction technology}

Due to the particularity of the environment of underwater sites, the technology of undisturbed solid extraction and reversible restoration of fragile underwater artifacts is faced with many difficulties:

(1) It is necessary to systematically evaluate and explore the existing state and potential influencing factors of fragile underwater remains.

(2) It is unknown about interfacial behavior between temporary solid materials and underwater artifacts and the influence of water medium on the reinforcement performance of solid materials.

(3) The existence of external factors such as water pressure and current around requires higher reinforcement strength of temporary reinforcement material.

(4) To ensure effective solidifying of underwater artifacts, temporary reinforcing materials should also be reversible, safe, and controllable. 


\section{Temporary undisturbed recovery technology}

The complexity of its surroundings makes underwater archaeologists challenging to obtain complete information, so the excavation process should follow the principle of minimum intervention, maximum limit retaining the original form of artifacts to prevent the loss of crucial archaeological information [53, 54]. The extraction and transfer of fragile artifacts by whole extraction methods are the most effective. The whole process requires: (1) ensuring the safety of artifacts: the reinforcement materials should have enough reinforcing strength to cope with the interference of external physical stress. (2) to ensure the entire state of fragile artifacts in site; (3) due to contact with the artifacts directly, the materials shall be no corrosive chemical interaction between the materials and the artifacts; (4) the strengthening materials can be removed in a controllable manner, without affecting the subsequent restoration and long-term preservation process.

Fortunately, the sublimable reinforcing agent can be used as a protective layer to extract fragile artifacts to ensure safe extraction. In contrast, the volatile nature of the material provides the whole reinforcement process is reversible. Cyclododecane $[55,56]$ and menthol [57] are temporary reinforcement materials for artifacts onland archaeological sites. According to the principle of melting and re-strengthening of the two materials, onland artifacts can be strengthened in their original state to ensure the safe transfer. Moreover, the two solidified materials can be safely removed by sublimation without affecting the actual state of the artifacts. At present, the research on the properties of menthol and cyclododecane has become mature. As the extraction materials of on-land archaeological artifacts, it has been used to excavate artifacts worldwide. Since the 1990s, cyclododecane has been used as a temporary solid material for land-based archaeological sites. Hangleiter [58] was the first to use the materials as a temporary reinforce agent for on-land archaeological sites and has gradually been widely used. Brown and Davidson [59] used cyclododecane to strengthen fragile lizard fossils and safely transfer them from Chicago to New York. Xia et al. [60] applied cyclododecane to the temporary reinforcement extraction of damaged stone armor from the Qin Terra-Cotta Warriors. In recent years, Han et al. have developed a kind of spice material-menthol, which has excellent properties such as suitable melting point, reinforcement, and penetration. Han et al. [61, 62] used menthol to reinforce painted temporarily remains in the pit of the Qin Terra-Cotta Warriors and the Tang Dynasty murals. However, due to the hydrophobicity of organic materials such as cyclododecane and menthol, such solid materials are more suitable for dry and fragile artifacts with low moisture content.

According to the research for on-land sites, the use of temporary solid materials can ensure the safe extraction of archaeological relics in their original state without affecting the existing state of artifacts. In recent years, researchers have been focusing on developing new materials and technologies suitable for fragile underwater remains, such as cryogenic extraction. According to the researchers in SASMAP Project [63], liquid nitrogen can create a local ultra-low temperature environment to freeze artifacts, water, and sediment into one whole unit. Moreover, proving that there is no significant change in the microstructure of fragile organic artifacts before and after liquid nitrogen freezing.

Recently, based on the research on cyclododecane and menthol applied in on-land archaeological sites, a food-grade flavor molecule-veratraldehyde is a potential material for temporary reinforcement of fragile artifacts underwater $[64,65]$. Our studies show that it has the physical characteristics of low melting point, insoluble in water, high density, and sublimation. Moreover, after melting, it can be kept in a supercooled liquid state for a long time in a closed container without crystallization and precipitation, which ensures phase stability during transferring to the underwater site. Through the extraction experiment in the laboratory, it is found that the material can be used to solidify fragile underwater artifacts in their original state, such as pottery pieces, scattered beadwork, broken porcelain, fragile lacquerware, and bamboo slips [66]. In addition, to further ensure the safety of fragile artifacts during extraction and transfer, a novel soft super-hydrophobic sponge with epoxy resin adsorbed can wrap the layer of the veratraldehyde solidified system, which can form a hard shell that is closely integrated with the inner solidified approach after curing [67-69]. After extraction, each reinforced layer can be removed safely and controllably (Fig. 3).

The above method for fragile underwater artifacts combines multi-step procedures such as temporary solidification, wrapping reinforcement, and block lift. It not only achieves the fixation but also ensures the safety of the extraction, but there is the disadvantage that the underwater operation process is relatively complicated. Besides, although the whole extraction process was successfully simulated in the laboratory, many potential problems and environmental impact factors (water pressure, water temperature, visibility) still need to be solved for practical application. 


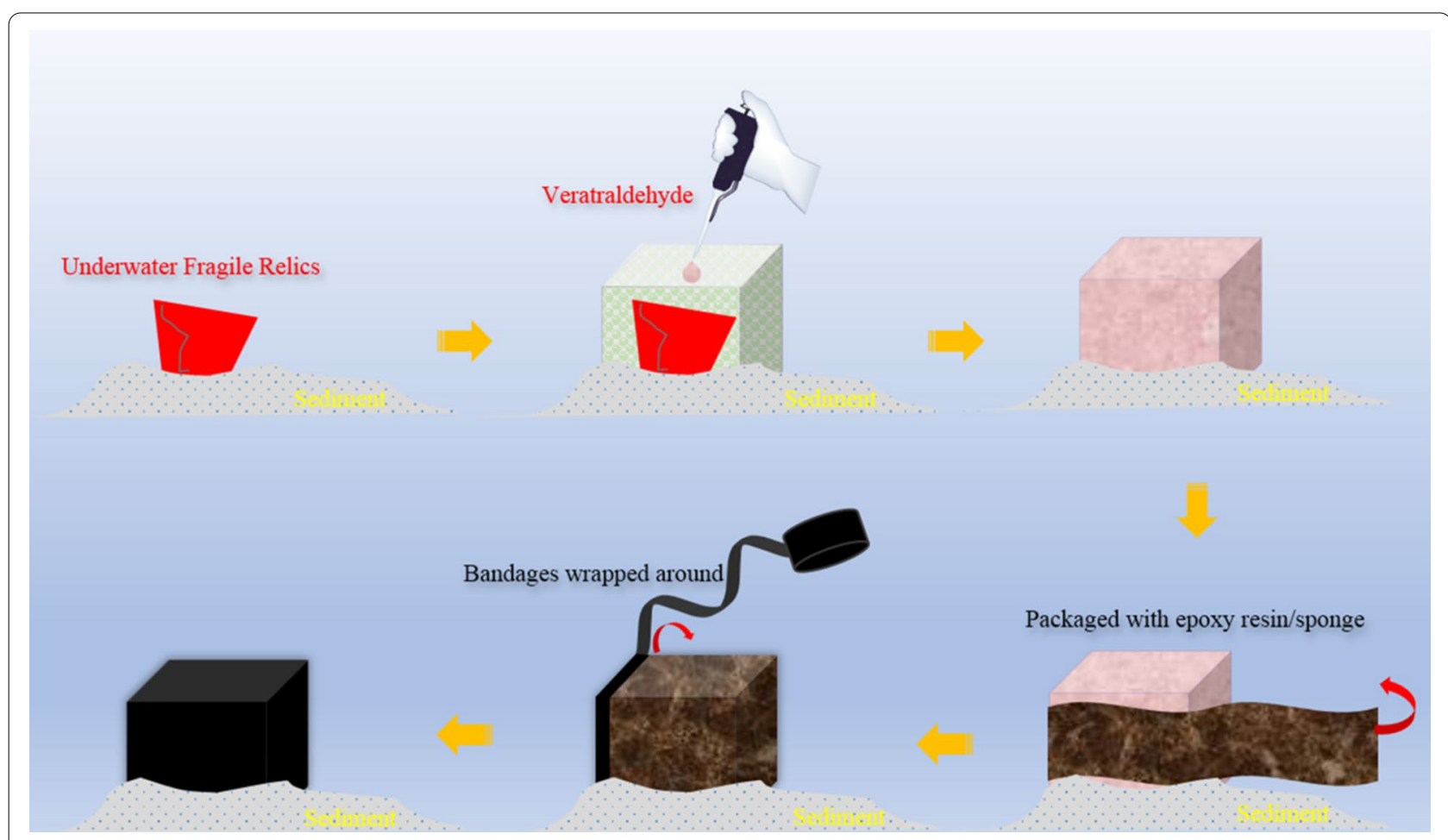

Fig. 3 The whole process of temporary solidifying and reinforcement of fragile underwater artifacts in archaeological sites

\section{Existing problems}

Both physical and chemical methods have been applied to the recovery of underwater objects. Physical methods involve relatively simple processes and are more suitable for underwater operations by divers. However, physical methods alone are often insufficient to ensure that underwater cultural relics can be extracted in their original form. The preparation of chemical components and the on-site operation processes are more complicated, and the impact of contact with cultural relics needs to be fully considered, but the existing underwater form of cultural relics can be well preserved. In addition, to ensure the recovery process's safety, the combination of the two is often most effective.

The existing problems:

(1) The development of new materials and technologies to extract underwater fragile artifacts is still in the initial stage. Considering the diversity of artifacts materials and underwater environment, the preservation situation presents complexity, and it is urgent to develop unique materials and technologies suitable for archaeological environments. Moreover, most of the research is more focused on the application, the system of basic research is relatively weak.

(2) Although several kinds of extraction materials for fragile underwater artifacts have been developed, they are still basically in the stage of laboratory research.
There are still many practical problems to be solved in the face of a complex submarine environment (visibility, water temperature, water pressure, etc.).

(3) There are many shortcomings in recovering underwater artifacts' protection and long-term preservation technology. A complete system of desalination, permanent reinforcement, biological or chemical corrosion and protective technology, removal of condensates, and longterm preservation technologies of artifacts has not been formed.

\section{Prospects}

(1) First of all, in-situ protection should be the primary choice for underwater cultural heritage preservation.

(2) The salvage excavation can be carried out selectively, but the extraction process needs to strictly follow certain principles, namely the "retain authenticity" and "long-term preservation" principle.

(3) Given the diversity of materials and surrounding environment of artifacts in the site, the preservation situation presents complexity; one kind of material and technology can only apply to a specific archaeological environment, so the research of cross-discipline and diversified new technology to particular artifacts will become an inevitable research trend.

(4) Develop a full range of underwater archaeology technologies (survey, recording, photography, 
excavation). At the same time, to develop in-situ detection instruments and equipment for real-time monitoring the surrounding environment of physical, chemical, and biological data of artifacts in underwater sites.

(5) Synchronously develop preservation technologies for the extracted relics, such as desalination and dehydration, removal of condensates, corrosion prevention, and long-term preservation.

\section{Conclusion}

In situ conservation and management of underwater cultural heritage should be a primary principle. However, on the premise of ensuring the safety and longterm preservation of artifacts, recovery and scientific research can be carried out for fragile artifacts in danger. Compared with land-based sites, the technology of extracting and transferring fragile underwater artifacts is relatively poor. The traditional extraction method is not suitable due to the fragile underwater remains. Researchers have made efforts and developed new materials and technologies in recent years. Though the developed technologies demonstrated that potential practical application was achieved, it still faces many challenges to be solved. In future research, it is necessary to solve the problem of undisturbed solidifying and safe extraction of fragile underwater artifacts with the help of multidisciplinary technology and equipment. At the same time, the long-term preservation of extracted cultural relics should also be put on the agenda.

\section{Acknowledgements}

The National Key R\&D Program of China (2020YFC1520504) is greatly acknowledged for its financial support.

\section{Authors' contributions}

XQC: writing, conceptualization, project administration, and investigation, KX and MC: conceptualization and editing, WH and KD: writing-review \& editing, SF: conceptualization, formal analysis, validation and editing. All authors read and approved the final manuscript.

\section{Funding}

This research is supported by the National Key R\&D Program of China (2020YFC1520504).

\section{Availability of data and materials}

All data generated are included in this article or available from the authors upon request.

\section{Declarations}

\section{Competing interests}

The authors declare that they have no conflict of interests.

\section{Author details}

${ }^{1}$ Cultural Property Protection Center, Ningbo University of Finance \& Economics, Ningbo 315175, China. ${ }^{2}$ School of Art and Archaeology, Zhejiang University, Hangzhou 310028, China. ${ }^{3}$ College of Humanities and Arts, Ningbo University of Technology, Ningbo 315211, China.
Received: 7 October 2021 Accepted: 7 January 2022

Published online: 15 January 2022

\section{References}

1. Leonard JR. American archaeologists in Cypriot waters: one nation's contributions to the underwater exploration of Cyprus' past. Near Eastern Archaeol. 2008;71:130-8.

2. Curry A. A stone age world beneath the Baltic Sea. Science. 2006;314:1533-5.

3. Guérin U. Underwater cultural heritage and the maritime past of Africa. J Marit Archaeol. 2012;7:1-2.

4. Staniforth M. Approaches to material culture in Australian maritime archaeology. Hist Archaeol. 2009;43:95-100.

5. Cvikel D, Ashkenazi D, Stern A, Kahanov Y. Characterization of a 12-pdr wrought-iron cannonball from the Akko 1 shipwreck. Mater Charact. 2013:83:198-211

6. Justin L. Opportunistic ports and spaces of exchange in Late Roman Cyprus. J Marit Archaeol. 2013;8:221-43.

7. Peters SJ. Archaeological wines: analysis and interpretation of a collection of wines recovered from the William Salthouse shipwreck (1841). Australas Hist Archaeol. 1996;14:63-8.

8. Chirikure S, Sinamai A, Goagoses E, Mubusisi M, Ndoro W. Maritime archaeology and trans-oceanic trade: a case study of the Oranjemund Shipwreck Cargo, Namibia. J Marit Archaeol. 2010;5:37-55.

9. Robert RS. Classical Greek measures and the builder's instruments from the Ma'agan Mikhael shipwreck. Am J Archaeol. 2006;110:195-203.

10. Mark S. The Abydos BG10 boat and implications for standardisation, innovation, and timber conservation in early dynastic boat-building. J Egypt Archaeol. 2012;98:107-26.

11. Castro F. In search of unique Iberian ship design concepts. Hist Archaeol. 2008:42:63-87.

12. Delgado JP. Secrets of a civil war shipwreck. Archaeology. 2011;64:48-62.

13. Curry A. The weapon that changed history. Archaeology. 2012;65:32-7.

14. Lippi MM, Bellini C, Trinci C, Benvenuti M, Sagri PM. Pollen analysis of the ship site of Pisa San Rossore, Tuscany, Italy: the implications for catastrophic hydrological events and climatic change during the late Holocene. Veg Hist Archaeobot. 2007;16:453-65.

15. Erlandson JM, Rick TC. Archaeology meets marine ecology: the antiquity of maritime cultures and human impacts on marine fisheries and ecosystems. Annu Rev Mar Sci. 2010;2:231-51.

16. Kenneth $\mathrm{RH}$. Indonesia's evolving international relationships in the ninth to early eleventh centuries: evidence from contemporary shipwrecks and epigraphy. Indones. 2010;90:15-45.

17. Needell CS. Cirebon: Islamic glass from a 10th-century shipwreck in the Java Sea. J Glass Stud. 2018;60:69-114.

18. Hamilton DL, Woodward R. A sunken 17th century city: Port Royal, Jamaica. Archaeology. 1984;37(1):38-45.

19. Raban A. The site and the excavations. The harbours of Caesarea Muritirna: results of the Cuesarea ancient harbour excavation project. $\mathrm{Br}$ Archaeol Rep Int Ser. 1989;1:491.

20. Kraft JC, Kayan I, Aschenbrenner SE. Geological studies of coastal change applied to archaeological settings. Archaeol Geology. 1985;57-84.

21. Ehud G, Mina W-E, Israel H, Avi G, Mordecai K, Omri L, Liora K-H, Hanan L. Atlit-Yam: a prehistoric site on the sea floor off the Israeli coast. J Field Archaeol. 1993;20(2):133-57.

22. Stright MJ. Archaic period sites on the continental shelf of North America: the effect of relative sea-level changes on archaeological site locations and preservation. Archaeological geology of the Archaic Period in North America. Geol Soc Am Spec Pap. 1995;297(13):1-147.

23. UNESCO. (2001). Convention on the protection of the underwater cultural heritage. http://unesdoc.unesco.org/images/0012/001260/126065e. pdf.

24. UNESCO. (2001). Convention on the protection of the underwater cultural heritage. http://www.unesco.org/culture/underwater/infokit_en/.

25. Sorna K, Konraad VB. Complications and effectiveness of in situ preservation methods for underwater cultural heritage sites. Conserv Manage Archa. 2012;14:469-78. 
26. Pournou A. Assessing the long-term efficacy of geotextiles in preserving archaeological wooden shipwrecks in the marine environment. J Marit Archaeol. 2018;13:1-14.

27. George FB. History beneath the sea. Archaeology. 1998;51(6):48-53.

28. Krause-Jensen D, Serrano O, Apostolaki ET, Gregory DJ, Duarte CM. Seagrass sedimentary deposits as security vaults and time capsules of the human past. Ambio. 2019:48(4):325-35.

29. Davidde B. Underwater archaeological parks: a new perspective and a challenge for conservation-the Italian panorama. Int J Naut Archaeol. 2002;31(1):83-8

30. Gonzalez-Duarte MM, Fernandez-Montblanc T, Bethencourt M, Izquierdo A. Effects of substrata and environmental conditions on ecological succession on historic shipwrecks. Estuar Coast Shelf S. 2018;200:301-10.

31. Pournou A. Biodeterioration of wooden cultural heritage. Berlin: Springer; 2020.

32. Ghoniem M. The characterization of a corroded egyptian bronze statue and a study of the degradation phenomena. Int J Conserv Sci. 2011;2(2):95-108.

33. Scott DA. A review of copper chlorides and related salts in bronze corrosion and as painting pigments. Stud Conserv. 2000;45:39-53.

34. Zhang X, Wallinder IO, Leygraf C. Mechanistic studies of corrosion product flaking on copper and copper-based alloys in marine environments. Corros Sci. 2014;85(4):15-25.

35. Bethencourt M, Fernandez-Montblanc T, Izquierdo A, Gonzalez-Duarte MM, Munoz-Mas C. Study of the influence of physical, chemical and biological conditions that influence the deterioration and protection of underwater cultural heritage. Sci Total Environ. 2018;613-614:98-114.

36. Hutchinson G. Threats to underwater cultural heritage. The problems of unprotected archaeological and historic sites, wrecks and objects found at sea. Mar Policy. 1996;20(4):287-90.

37. Zamora TV. The impact of commercial exploitation on the preservation of underwater cultural heritage. Museum Int. 2009;60(4):18-30.

38. James PIV. Salvaging sunken shipwrecks: whose treasure is it? A look at the competing interests for Florida's underwater riches. J Land Use Environ Law. 1994;9(2):347-73.

39. Flatman J. Conserving marine cultural heritage: threats, risks and future priorities. Conserv Manage Archa. 2013;11(1):5-8.

40. Foster KJ. Threatened James River shipwreck and historical sites. Hist archaeol. 1992;26(4):58-68.

41. Hall CM, Baird T, James M, Ram Y. Climate change and cultural heritage: conservation and heritage tourism in the Anthropocene. J Herit Tour. 2015:11(1):10-24.

42. Howard AJ. Managing global heritage in the face of future climate change: the importance of understanding geological and geomorphological processes and hazards. Int J Herit Stud. 2013;19(7):632-58.

43. Perry J. World Heritage hot spots: a global model identifies the 16 natural heritage properties on the World Heritage List most at risk from climate change. Int J Herit Stud. 2011;17(5):426-41.

44. Macleod ID, Viduka A. The effects of storms and diving activities on the corrosion rate across the SS (1911) site in the Great Barrier Reef. AICCM Bull. 2014;32(1):134-43.

45. Gregory D. Experiments into the deterioration characteristics of materials on the Duart Point wreck site: an interim report. Int J Nauticul Archaeol. 1995;24(1):61-5

46. Macleod ID. Monitoring, modelling and prediction of corrosion rates of historical iron shipwrecks. Corrosion and Conservation of Cultural Heritage Metallic Artefacts, 466-77.

47. Mcninch JE, Wells JT, Drake TG. The fate of artifacts in an energetic, shallow-water environment: Scour and burial at the wreck site of Queen Anne's Revenge. Southeast Geol. 2001;40(1):41-6.

48. Manders M. In situ preservation: 'the preferred option.' Museum Int. 2008:60:31-41.

49. Secci M. Protection versus public access: two concepts compared within the Italian underwater cultural heritage management system. J Marit Archaeol. 2011;6(2):113-28.

50. Crisci GM, Russa MFL, Macchione M, Malagodi M, Palermo AM, Ruffolo SA. Study of archaeological underwater finds: deterioration and conservation. Appl Phys A. 2010;100(3):855-63.

51. Khakzad S, Van Balen K. Complications and effectiveness of in situ preservation methods for underwater cultural heritage sites. Conserv Manage Archa. 2012:12:469-78.
52. SASMAP Project: www.sasmap.eu.

53. Sease C. A conservation manual for the field archaeologist. Los Angeles: UCLA Institute of Archaeology; 1987.

54. Muros V. Conservation practices on archaeological sites: principles and mechanisms. J Am Inst Conserv. 2015:54:114-6.

55. Vernez D, Barthélémy W, Tomicic C, Plateel G, Charrière N, Bruhin S. Cyclododecane exposure in the field of conservation and restoration of art objects. Int Arch Occ Env Hea. 2011;84(4):371-4.

56. Bruckle I, Thornton J, Nichols K, Strickler G. Cyclododecane: technical note on some uses in paper and objects conservation. J Am Inst Conserv. 1999;38(2):162-75.

57. Han $X$, Huang $X$, Zhang BJ. Laboratory research into the use of menthol as a temporary consolidant for conservation on archaeological excavations. Archaeometry. 2018;60(6):1334-45.

58. Hangleiter HM, Jäers E. Zeitschrift für Kunsttechnologie. Konservierung Flüchtige Bindemittel. 1995;9:385-92.

59. Brown M, Davidson A. The use of cyclododecane to protect delicate fossils during transportation. J Vertebr Paleontol. 2010;30(1):300-3.

60. Xia Y, Weichert M, Zhang Z, Zhou T, Ma S. Application of cyclododecane on one stone armour set excavation and restoration. Sci Conserv Archaeol. 2005;17(2):31-5.

61. Han X, Rong B, Huang X, Zhou T, Wang C. The use of menthol as temporary consolidant in the excavation of Qin Shihuang's Terracotta Army. Archaeometry. 2013;56(6):1041-53.

62. Han X, Zhang B, Luo H, Huang X, Su B. A study on the use of menthol in the emergency removal of tomb murals. Dunhuang Research. 2016:159(5):142-8.

63. Petriaggi BD, Gregory DJ, Dencker J. Recovery of fragile objects from underwater archaeological excavations: new materials and techniques by SASMAP project. Lecture Notes Comput Sci. 2014;8740:625-34.

64. Chen X-Q, Zhang B, Zhang Z. Application of veratraldehyde as a temporary consolidant for relics at underwater cultural heritage sites. Archaeometry. 2019;61(6):1417-29.

65. Chen X-Q, Zhang B, Zhang Z. A novel method of temporary solidification and extraction of underwater fragile relics in their original state. Int J Adhes Adhes. 2021;104:102724.

66. Wang $X$, Zhang B, Hu Y. Research on extraction of fragile bamboo slips by underwater temporary solidification in original state. J Cult Herit. 2021;51:174-81.

67. Chen X-Q, Xie L, Wang F, Wu Y, Zhang B, Zhu L. Temporary consolidation and packaging of fragile cultural relics at underwater archaeological sites to maintain their original state during extraction. Archaeometry. 2020;62(5):1067-77.

68. Chen X-Q, Zhang B, Xie L, Wang F. MWCNTs polyurethane sponges with enhanced super-hydrophobicity for selective oil-water separation. Surf Eng. 2020;36(6):651-9.

69. Wang F, Chen X, Wang X, Zhang B, Hu Y, Zhu L. Technique of temporary undisturbed reinforcement extraction of fragile lacquerware from shipwrecks. J Marit Archaeol. 2021;16:27-38.

\section{Publisher's Note}

Springer Nature remains neutral with regard to jurisdictional claims in published maps and institutional affiliations. 